\title{
Impact of Belief Systems on the Management of Child Malnutrition: The Case of Talensis of Northern Ghana
}

\author{
Christopher S. Boatbil (Corresponding Author) \\ Department of Liberal Studies, School of Applied Sciences and Arts \\ Bolgatanga Polytechnic, Ghana \\ E-mail: csboatbil@yahoo.com
}

Chris Bambey Guure

Department of Biostatistics, School of Public Health, University of Ghana, Accra, Ghana

E-mail: cbguure@ug.edu.gh

Azerikatoa D. Ayoung

Department of Liberal Studies, School of Applied Sciences and Arts

Bolgatanga Polytechnic, Ghana

E-mail: azerikatoa@gmail.com

Received: August 2, 2014 Accepted: August 15, 2014 Published: December 1, 2014

doi:10.5296/jfs.v3i1.6048ＵRL: http://dx.doi.org/10.5296/jfs.v3i1.6048

\begin{abstract}
Child malnutrition is a global public health problem which efforts are being made to minimize or eradicate. Though many studies have been conducted to explore its incidence, patterns and causes, the issue of 'Local Beliefs' remain poorly understood in most communities. The purpose of this study is to understand local awareness of malnutrition, types of beliefs regarding its causes, specific traditional treatments and willingness to treat child malnutrition traditionally. The study largely depended on qualitative approaches such as focus group discussions and in-depth interviews complemented by a minimal use of quantitative tools such as questionnaires, to gather data from 120 household members. Sampling methods included Clustering, simple random and lottery methods. Whilst percentages, pie charts and bar graphs were used to analyze quantitative data, an interpretative approach was employed for qualitative
\end{abstract}




\section{Macrothink

data. Although Local awareness of child malnutrition was high, yet it was not seen as a serious health burden. The beliefs about the causes of child malnutrition included a child offending a 'Tobig god' by eating dry flour, eating meat sacrificed to 'Tobig god', sucking of 'bitter breast milk', eating chicken though he/she prohibits it, and 'Sama'(living things blocking breast milk). Treatments included consulting soothsayers to determine modes of pacification to offended gods, drinking water with fowl droppings in it and smearing grinded guinea corn malt on mothers' breasts. The study also showed that majority of respondents preferred to treat child malnutrition traditionally.

Keywords: Malnutrition, Children, Beliefs, Social, Causation, Management, Talensis, District 


\section{Introduction}

Child malnutrition is a global and lethal public health problem particularly among developing countries [1]. According to [6], there are three main forms of child malnutrition namely Protein Energy Malnutrition (PEM), Mineral Deficiency Malnutrition (MDM) or a combination of both. However, PEM is the most popular researched theme among social science disciplines perhaps because MDM deals with the clinical or biological aspects. PEM is represented by three indices of stunting defined as chronic under nutrition, underweight indicating acute under-nutrition and wasting meaning weight loss [17].

The outcomes of many studies paint gloomy pictures of malnutrition situations globally. In absolute terms, nearly 800 million persons are affected with children being the hardest hit [2]. According to [17], about 44\%, 22\% and 4\% of under-fives suffer from stunting (low height-for-age), underweight (low weight-for-age) and wasting (low weight-for-height) respectively. In Africa, the number of undernourished children continue to increase and chronic malnutrition still persists as a serious problem [5].

Malnutrition is associated with deleterious consequences on children and the society at large being responsible for over half of childhood deaths and the high percentage of children failing to reach the normal international standard growth [2, 5, 11]. Corroborating this view, [19] posits that about half of the 4 million deaths of under-five children annually are attributable to malnutrition [9]. As a global response, the fourth Millennium Development Goals (MDG) was set to reduce under-five mortality by two thirds $\left(2 / 3^{\text {rd }}\right)$ by the year 2015 . Reducing the magnitude of child malnutrition is an integral part of this process. However, child malnutrition situation is not getting any better in some parts of the developing world. In Ghana for instance, its incidence worsened between 2003 and 2006 [6].

The contribution of social science researchers towards reducing the burden of child malnutrition globally hinges on determining its incidence and causes. Causes of child malnutrition generally are categorized into three major factors; immediate, underlying and basic factors. The direct factors include inadequate food intake and diseases whilst the underlying factors comprise food security at the household level, public health problems and social care of the environment. The basic factors among others are political, economic, socio-cultural and physical environment [9, 10, 11, 12]. Aside these factors, local beliefs regarding causes of child malnutrition contributes to its persistence in many places since health seeking behaviors for children is sometimes dependent on traditional knowledge, beliefs and perceived causes of the specific illness [1, 9].

The causal factors of malnutrition can also be grouped under either the germ (Scientific) or social causation theories [6]. The germ theory refers to scientific, biological or clinical causes of child malnutrition whilst the social causation theory is about cultural beliefs regarding causes of child malnutrition. With the social causation theory, social factors rather than viruses or bacteria promote child malnutrition. Illnesses are therefore thought to be of mystical origins and caused by devils, witchcraft, a spell or some supernatural forces. For such ailments, modern medicine is considered useless or inappropriate and is the last option. [3, 9, 14]. 
In some Indian communities growth retardation among children has been attributed to feeding them with milk curds (Innocent et al., 2008). In Kenya too residents believe child malnutrition is caused by sexual transgressions (violation of postpartum sexual) which attract the wrath of gods and also witchcraft. They also believe when children suck whilst mothers are pregnant, fetuses become jealous and pass "ekhiria” (marasmus) to older ones. Upholding such sexual transgression belief inadvertently reduces parity rate and improves the health of both mothers and children. Furthermore, residents believe witches are capable of using human faeces to harm individuals or whole families in various ways including malnutrition. According to [7], Malaysian children are prohibited from eating green and yellow vegetable since it is seen as the cause of exophthalmia (eye disease due to vitamin A deficiency), worsen sicknesses and allows worms infestation. In Somalia, local people recognize child malnutrition exists and that its acute form is associated with poor food, sanitation and social causes. They do not see child malnutrition as a serious public health problem. Normal child malnutrition is treated by giving the child more food and medicine but with acute ones, the swollen limbs, stomachs and faces of children are burnt to remove the fluids. If it is thought to be caused by the evil eye, items such as faeces of elephant, hooves of donkey, hyena's skin, garlic and Ubuore leaves are burnt and steamed with the smoke and given to the child. This makes the child to sweat, sneeze out lots of phlegm as a sign of exorcising the evil from the head [15].

It is clear that traditional beliefs regarding causes of child malnutrition exist and are not the same across all communities since such causes hinge on society's cultures and philosophies. Therefore, it is expedient identifying such beliefs in different communities to understand the prevalence, patterns, causes and management of malnutrition and other diseases, to help stem the problem of malnutrition holistically. In the view of this study, the existence of beliefs regarding child malnutrition is partly responsible for the huge reservoirs or hordes of malnourished children in many rural communities. Thus such beliefs pose serious challenges to governments, public health practitioners and other development-related institutions attempting to eliminate or reduce the magnitude of the problem. However, the social causation perspective of diseases has not received adequate academic attention in Ghana and in particular the Talensi area of Upper East Region. It is in this regard that this paper seeks to explore the local awareness about child malnutrition, beliefs held about malnutrition, traditional management options and local preferences for traditional approaches in the treatment of child malnutrition.

\section{Objectives of the Study}

The study was designed to:

i. $\quad$ explore local awareness about the prevalence of child malnutrition among the Talensis;

ii. examine traditional beliefs regarding the causes of under-five malnutrition and management approaches;

iii. draw implications for the prevalence of malnutrition and provide suggestion for health policy development. 


\section{Study Setting}

The Talensi district is located in the Upper East Region of Ghana with Tongo as its capital. It is bordered by Bolgatanga Municipal to the North, West and East Mamprusi Districts to the South, Kassena-Nankana District at the West and Nabdam District to the East. The district lies between latitude 10' 15" and10' 60" north of the equator and longitude 0 ' 31" and 1'0.5” and west of the Greenwich meridian [16]. It has a total land area of $912 \mathrm{~km}^{2}$ and can be divided into three zones of East, Central and West. Villages in the East include Namoalug, Sheaga, Gaare, Datoku, Yamerig, Duusi, Tindongo, Sawaliga, Buug woog, Bugaban, Gban Sok, Kolpelig and Yal. The central consists of villages such as Tongo, Gbeogo, Yarzuri, Baari, Beog, Zandoya, Tenzug/Santeng, Sakorig, Wakii and Kpatia. The Talensi-west villages include Yinduri, Pusunamogo, Balungu, Pwalugu, Winkogo, Shia, and Separt.

The main source of livelihood is crop agriculture which employs about $90 \%$ of the working class [16]. Other activities undertaken include livestock rearing, poultry production fuel wood extraction, food processing, mining and tourism. The rearing of larger animals like cattle is the preserve of males but females can rear smaller animals (i.e. goats, sheep and poultry). Irregular rainfall and declining soil fertility have resulted in low crop yields and inadequate levels of food production, thus making the district a food deficit area. The vegetation falls within the guinea savanna zone and can at best be described as parkland. Owing to this environment, farmlands appear to be dwindling in quality amidst rising population growth. This poses severe strains on household resources and incomes [16].

The secondary sector can be described as dormant and largely comprises of a defunct tomato factory, cotton ginnery and two quarries. Few people engage in the production of handicrafts such as 'Zana' mats, baskets, hats, leather, tanned leather bags, foot wears and smocks as well as locally made fans and brooms from straw. The District has 15 health facilities comprising of 2 health centers, 2 clinics and 11 CHPS zones. Other health facilities include chemical stores and traditional healers. The district has a total of 96 schools and these include 21Kindergartens schools, 45 Primary Schools, 2 SHS, 26 JHS, 1 school for the deaf and 1 Vocational school. About $70 \%$ of these schools are deprived of portable water, good sanitation facilities and standard classroom furniture [16].

Among the Talensis, child malnutrition is an age old sickness though it is not recognized as widespread since children are considered as malnourished only when they are visibly emaciated. The disease can therefore be described as a 'Silent Killer' because of its imperceptible nature and misunderstood causal factors. According to a study in Tongo, Stunting and Wasting were $52.6 \%$ and $55.6 \%$ respectively during pre-harvest season whilst during post-harvest season their levels also stood at $52.2 \%$ and $47.9 \%$ respectively [11].

\section{Methodology}

The study employed a combination of sampling and data collection tools. The analyses were performed via qualitative and quantitative (descriptive statistics) approaches. The district was zoned into three clusters of Talensi-East, Talensi-Central and Talensi-West. This clustering was based on the fact that those in the "East" are generally considered Nabdams, the "Central" 
are Talensis and the "West", a mixture of mid-Gurenes and Talensis. One village or community representing a cluster was selected through a simple random sampling technique using village names. The selected villages were Namoalug from the East, Gbeogo from Central and Balungu from the West. Total sample size for household questionnaire was 120 and was equally divided among the three selected communities. A total of 30 participants for both focus group discussion and in-depth interviews were used. Six focus groups each with four participants were organized. For each of the three selected communities, there were two focus groups, one for males and the other for females. The total participants for the focus groups were 24. Furthermore, 6 in-depth interviewees were used also with gender consideration.

Subjects for household questionnaire were selected through multi-stage sampling. First, names of every house of selected communities were written on pieces of paper and the required sample size selected through random sampling. In selected houses, households were selected by a lottery method and subjects from such households were selected based on adult members who were present and also willing to participate. The household questionnaire focused on five socio-demographic variables such as sex, educational status, occupation, religion, and age of respondents. Also, questionnaires contained issues on respondent knowledge or awareness of child malnutrition and their attitudes towards adopting traditional approaches in treating the condition. Both focus group discussants and in-depth interviewees provided qualitative information on the beliefs regarding causes of child malnutrition and the various treatment methods. Purposive sampling techniques were also adopted in the selection of participants for focus group discussions and in-depth interviews. These methods were employed mainly because of the highly the cultural perspective of the study. These qualitative methods were employed to obtain the fine grain details of beliefs about child malnutrition. Both focus group discussants and in-depth interview participants were knowledgeable people such as religious leaders, traditional healers, traditional birth attendants (TBAs), elderly persons like grandmothers and fathers. In analyzing the data, bar graphs, tables, pie charts were used for the quantitative data whilst an interpretive method through the use of dialog boxes was used for the qualitative data.

\section{Results}

\subsection{Local knowledge or perceptions about child malnutrition}

Child malnutrition is locally known as "borihn” among the Talensi people. Local awareness about the disease was widespread and was nearly 100\% among respondents in selected communities of the study area. Figure 1 shows the distribution of awareness in terms of those aware, those not aware and those who were unable to state their positions to the question posed. 


\section{Fig 1:Percentage of respondents aware of prevalence of}

\section{malnutrition}

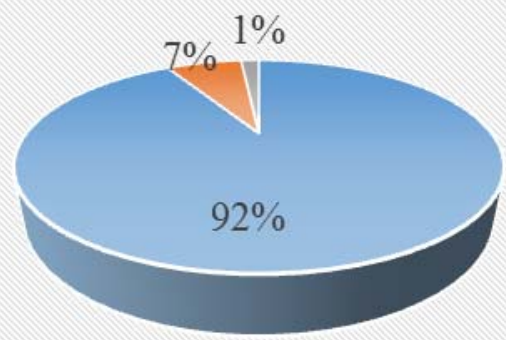

- Yes

$-\mathrm{NO}$

- Don't know

Spatially, child malnutrition awareness was almost equally distributed among the three communities. The levels were 37\%, 38\% and 36\% for Namoalug, Gbeogo and Balungu respectively. Almost all focus group discussants and in-depth interview participants were also aware of the ailment. However, most did not recognize child malnutrition as a serious burden among the population. Figure 2 illustrates the distribution awareness among selected study villages.

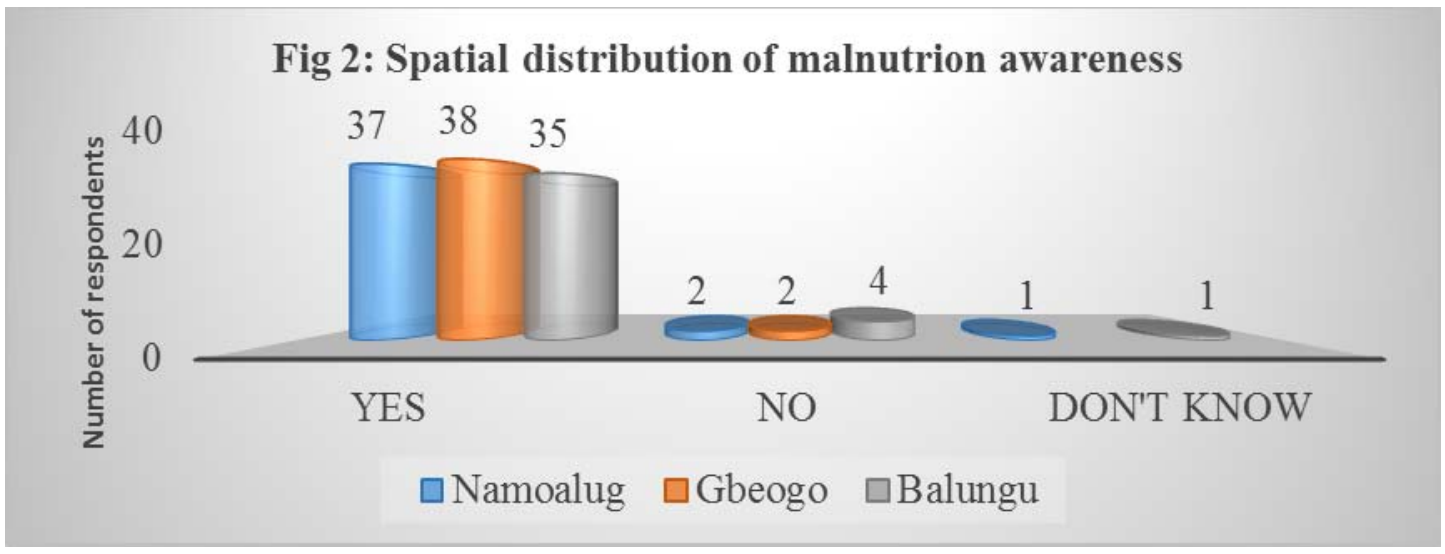

Out of a total of 120 household respondents 69 were males representing $57.5 \%$ and 41 were females representing 42.5\%. Within the various communities, awareness differed among socio-demographic groups. Except in the case of Balungu, more males in both Namoalug and Gbeogo were aware of child malnutrition than females as shown in tables 1-3.

Table 1. Sex of respondents and awareness of child malnutrition in Namoalug

\begin{tabular}{|l|c|c|}
\hline Responses & Male & Female \\
\hline Yes & 20 & 17 \\
\hline No & 1 & 1 \\
\hline Don't know & 1 & 0 \\
\hline Total & 22 & 18 \\
\hline
\end{tabular}


Table 2. Sex of respondents and awareness of child malnutrition in Gbeogo

\begin{tabular}{|l|c|c|}
\hline Responses & Male & Female \\
\hline Yes & 29 & 9 \\
\hline No & 2 & 0 \\
\hline Don't know & 0 & 0 \\
\hline Total & 31 & 9 \\
\hline
\end{tabular}

Table 3. Sex of respondents and awareness of child malnutrition in Balungu

\begin{tabular}{|l|c|c|}
\hline Responses & Male & Female \\
\hline Yes & 12 & 23 \\
\hline No & 4 & 0 \\
\hline Don't know & 0 & 1 \\
\hline Total & 16 & 24 \\
\hline
\end{tabular}

At all levels of education, more people were aware of the incidence of child malnutrition in the study area. However, except respondents with primary education, the extent of awareness increased with increasing levels of education as evidenced in Figure 3.

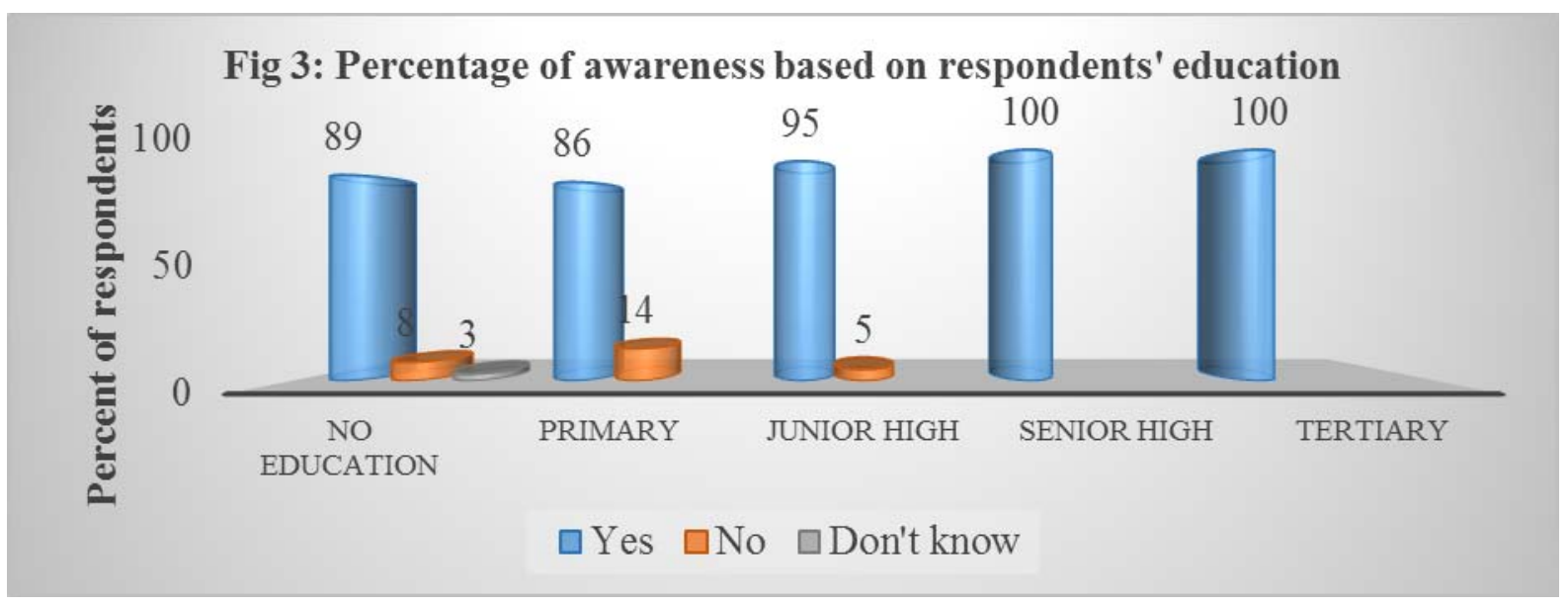

\subsection{Beliefs regarding child malnutrition and respective management approaches}

Table 2 provides a summary of various beliefs that Talensis traditionally hold as causes of child malnutrition and their respective treatments.

Table 2. Beliefs about causes of child malnutrition and respective treatments

Cause 1: Most houses have gods called "Dong" or "Tobig”. These are meant to repel sickness and help in childbirth. But should a child offend the gods, they become angry and cause the child to become malnourished.

Treatment 1: Parents usually go to soothsayer to find the cause. When it is revealed that the cause is as a result of an offense to a Tobig, the soothsayer will through communication with the god find what 
animal can be used to pacify it to remove the malnourishment from the child.

Cause 2: For houses of some “Tengdanas” (landowners), children are forbidden from eating dry flour. If they do so, they will get malnourished.

Treatment 2: Animals are used to pacify gods when the child takes dry flour.

Cause 3: There are some villages where first born children (male and female) are prohibited from the consumption of chicken. Children who go against it will also get malnourished. Some of the villages that practice these prohibitions in the Talensi area are Namoalug, Sheagah, Tongo, Winkogo, Balungu, Zoo, Yameriga, Beog, major sections of Gbani.

Treatment 3: According to the villagers, they treat it by soaking fowl faeces and allowing particles to settle before giving the water to such children to drink to eradicate the malnutrition.

Cause 4: For suckling children, "biihtoog” (bitter breast milk) can cause malnutrition. This cause is first identified when the child sucks the mother's breast milk and vomits it. To be sure, a second stage is to extract the breast milk into a container and an ant is caught and dropped in the milk. When the ant dies, it is detected that the milk is bitter and so is the cause of the child getting malnourished.

Treatment 4: Cause 4, according to the villagers can be treated by traditional healers.

Cause 5: According to the traditional people, "living things" referred to as "sama” can block flow of breast milk and result in the child being malnourished.

Treatment 5: We treat this by grinding guinea corn malt and smearing on mother's breast for about one to two days before the child is allowed to suck.

Cause 6: When children wrongly eats meat of animals or birds sacrificed to sacred gods called "Baar-kiha". This meat must only be eaten by those selected by the gods.

Treatment 6: Such a cause is identified through soothsaying and pacification done to stop the symptoms of child malnutrition.

Many women use these traditional methods because their husbands believe in treating child malnutrition traditionally. Some mothers who are advised to send their children to hospital and rehabilitation centers for treatment do so but when they come back, they complement it with local treatment.

The study revealed that Talensi people held several beliefs regarding the causes of child malnutrition which also formed the bases for the kinds of treatments that malnourished children were given. When asked about general positions regarding treating child malnutrition traditionally, 69 respondents representing 57.5\% indicated their support whilst 51 respondents representing $42.5 \%$ did not support it.

\subsection{Socio-demographic characteristics and traditional approach}

More males than females favoured treating child malnutrition traditionally. Apart from respondents with tertiary education, more people at various categories of the educational ladder accepted treating the phenomenon tradtionally. Whilst a large proportion (80\%) of respondents 


\section{Macrothink Institute $^{\mathrm{TM}}$}

agreed to the use of traditional method, $60 \%$ of Muslims did with none being Christians. Also, apart from the divorced and widowed, more respondents of various marital status agreed to treating child malnutrition traditionally. In terms of occupation, majority of those who disagreed to the treatment of child malnutrion trationally were traders, followed by housewives, government workers and farmers. The rest had more people agreeing but farmers topped with over 90\%. The following figures (Fig 4, 5,6 and 7,) provide vivid illustrations of the discussions in this section.

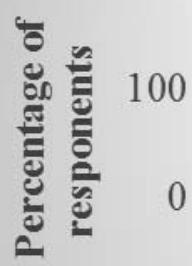

Fig 4: Sex and traditional approach

78.3

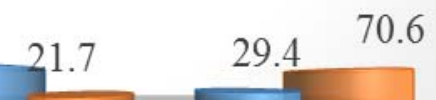

MALE

FEMALE

$\square$ Agree $\quad \square$ Disagree

Fig 5: Education and tradtional approach

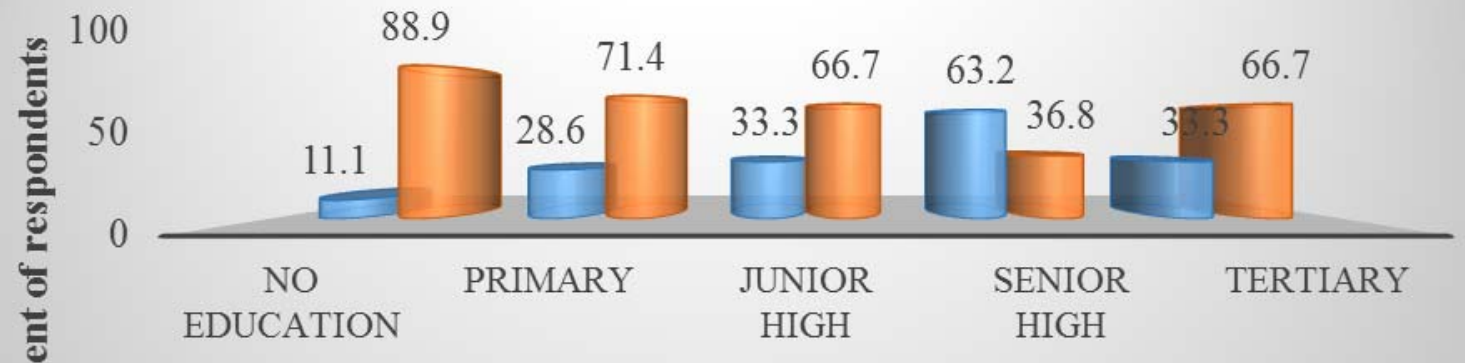

$\square$ Disagree $\square$ Agree

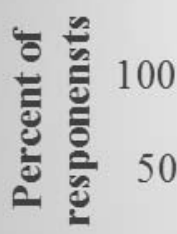

Fig 6: Religion and tradtional approach

100

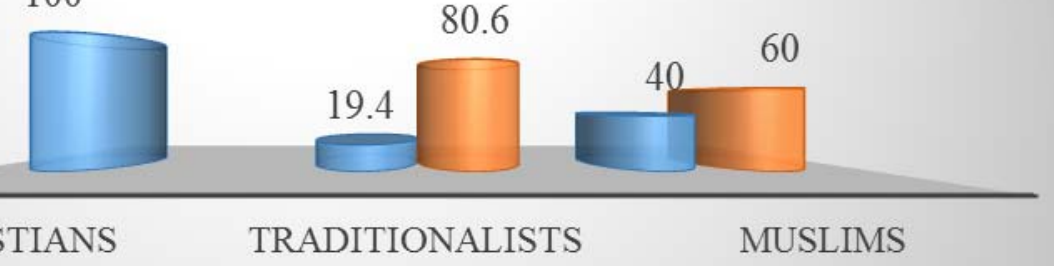

$\square$ Disagree $\square$ Agree 


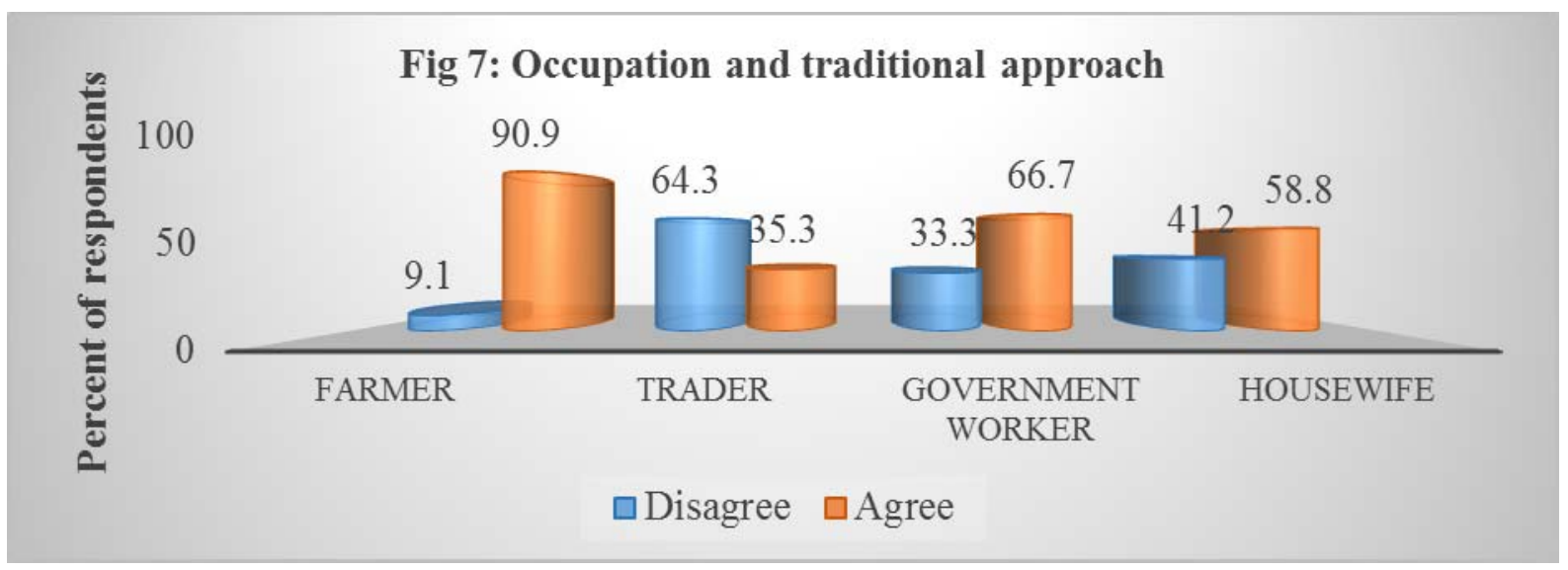

\section{Discussions}

There was high level of local awareness of child malnutrition as a disease. This situation is good and might be as a result of word of mouth transmission of cultural knowledge, health education by health institutions and through the electronic and print media. However, as is the case in [15], local people of the study area did not see malnutrition as a serious public health burden because of the absence of visible signs of emaciation. This makes the disease more precarious and thus its description as a 'Silent Killer' in the study area. With these perceptions, parents do not pay attention to malnourished children who may gradually develop weak immune systems and become more susceptible to other infections thus contributing to the high mortality rates of children in the developing world [5, 17].

The study also revealed prohibitions of food like chicken and fowl eggs by only first born male and female of every couple in communities such as Namoalug, Sheagah, Tongo, Winkogo, Balungu, Zoo, Yameriga, Beog, and major sections of Gbani, whereas in India, food prohibited by children include milk curds according to [9] and green and yellow vegetable in Malaysia [7]. Even though the group of people who prohibit chicken in the study area is not relatively too large when compared to the area's total population, it can be argued majority of family members are denied cheap source of protein as preparing family soup with chicken is frowned upon.

Residents of the study area still hold on to several beliefs as being the causes of child malnutrition. These beliefs were children offending gods such as 'Dong” or "Tobig', children in Tengdanas houses eating dry flour, first born males and females of couples in some communities eating chicken, bitter breast milk, living things blocking flow of breast milk and children wrongly eating meat of animals or birds sacrificed to sacred gods (Baar-kiha). Though people in other parts of the globe also have beliefs regarding causes of child malnutrition, traditional Malaysians believe children fed with green and yellow vegetables develop Exophthalmia [7] whilst some communities in India think feeding children with milk curds leads to growth retardation [9]. 
In the study area, more than half of the population (57\%) supported treating child malnutrition traditionally. From a gender perspective, a higher percentage of males (78.3\%) supported treating child malnutrition traditionally compared to females (29.4\%) as indicated in figure 4. This pattern could be attributed to health education to mothers regularly receive upon visits to health facilities. It could also be attributable to perceived greater female acceptance of non-traditional faiths. Despite this trend, the patriarchal society and unfair distribution of economic wealth make decisions on health-seeking behavior for children male dominated. Thus the position of women in terms of treating malnourished children will remain meaningless if the cooperation of males are not sought. Furthermore, a large proportion of respondents with tertiary-type education did not support treating child malnutrition traditionally but they also constituted an insignificant proportion of the sample size and population. The willingness to treat child malnutrition traditionally and level of education appear to be inversely related. More Christians objected to the use of traditional methods followed by Muslims and people of the Traditional faith in descending order. Famers had the majority of people who preferred treating malnutrition cases traditionally. This might be because majority of them may equally be practicing the traditional faith compared to other occupations and also because of their level of education.

\section{Conclusions and Recommendations}

A larger percentage of respondents did see malnutrition as a serious public health burden of the Talensi society. Many respondents still held traditional beliefs about the causes of child malnutrition which defined the mode of treatment affected children were given. More males held these beliefs as compared to females. Thus more males equally favoured traditional means of treating child malnutrition than females did. However, it was not uncommon to find some women or mothers absconding with their malnourished children from rehabilitation centers back to their villages for traditional treatment. The society is said to be patriarchal with unequal gender opportunities in terms of household decision-making and wealth and so public education about child malnutrition which is always given to mothers at health facilities would be ineffective if males are not taken into consideration. Women would be unable to influence men to accept modern medical knowledge and approaches to treating child malnutrition. Indeed, in most cases, treatments of child malnutrition are misdirected as it does not focus on the causative factors but other social factors. This implies that children with even visible signs of child malnutrition are not treated. This might be responsible for the large magnitudes of malnourished children in the study area and other parts of Upper East Region of Ghana.

Based on the preceding conclusions, the following recommendations would be important in helping to minimize the problem of child malnutrition in the study area and elsewhere with similar conditions.

- There should be more intensive public education concerning the incidence of child malnutrition, emphasizing the fact that absence of visible symptoms does not mean the burden of disease is not serious and the children's nutritional statuses should be regularly observed scientifically. 


\section{Macrothink}

Journal of Food Studies ISSN 2166-1073 2014, Vol. 3, No. 1

- Public education about child malnutrition and treatment using modern methods should also be targeting men or fathers in particular because they are the leaders and decision makers of families. Other target groups should be farmers and people who practice the African Traditional Religion.

- Residents of the study area should be motivated in various ways to send malnourished children to modern health facilities for attention.

- Similar studies should be conducted in other communities in Ghana to unravel all beliefs regarding causes of child malnutrition. It is also recommended that further studies should be carried out to understand the influence of economic factors on willingness to use traditional methods in the treatment of child malnutrition. Similarly, studies should be conducted to explore variations of local support among types of traditional treatment methods identified in this study.

\section{References}

Abubakar, A., Holding, P., Mwangome, M., \& Maitland, K. (2011). Maternal perceptions of factors contributing to severe under-nutrition among children in a rural African setting. Rural and remote health, 11(1), 1423.

Benson T., Palmer T., \& Johnson-Welch, C. (2003). Crossing Boundaries to Reduce Malnutrition: An Institutional Study of Agriculture and Nutrition in Uganda, Mozambique, and Nigeria-Report submitted to ICRW under the Agriculture-Nutrition Advantage project document. International Food Policy Research Institute (IFPRI), Washington, DC

de Blij, H. J. (1996). Human Geography: Culture, Society and Space. John Wiley \& Sons, Inc. Ebrahim, G. J. (1993). Pediatrics Practice in Developing countries ( $2^{\text {nd }}$ edition). London and Basingstoke: Macmillan.

FAO (2008). "Soaring Food Prices: Facts, Perspectives, Impacts and Actions required”, background paper prepared for the High-Level Conference on World Food Security: The Challenges of Climate Change and Bioenergy, Rome, June 3-5. [Online] Available: www.fao.org/foodclimate/conference/en/ (September 10, 2010).

Ghana Health Services, (2007). Annual Report, Accra: Ghana Health Service.

Dufour, D. L., Goodman, A. H., \& Pelto, G. H. (2013). Nutritional anthropology: Biocultural perspectives on food and nutrition. New York: Oxford University Press. GSS, 2003. Ghana Demographic and Health Survey. Calverton, MD: Ghana Statistical Service (GSS) and Macro International.

Onyesom, I., Onyesom, C., Ofili, M. I., Anyanwu, B. E., \& Uzuegbu, U. (2008). Effect of cultural beliefs and forbidden foods on the ABCD parameters of nutrition among some children in Nigeria. Middle-East J Sci Res, 3(2), 53-6.

Keeble, J., \& Keeble, R. (2006). A qualitative study of beliefs about food relating to child nutrition in the Lower Jimi Valley. Papua New Guinea Medical Journal, 49(3/4), 162. 


\section{Macrothink}

Journal of Food Studies ISSN 2166-1073 2014, Vol. 3, No. 1

Mariama, A. (2003). Social dynamics and infant feeding practices in northern Ghana, Research Review NS 19.2, 85-98

Muhammad, F. A. \& Naleena, M. D. (2012). Nutritional Status and Eating Practices Among Children Aged 4-6 Years Old in Selected Urban and Rural Kindergarten in Senghor, Malaysia, Asian Journal of Clinical Nutrition, 4(4), 116-131. http://dx.doi.org/10.3923/ajcn.2012.116.131

Nabila, J.S. (1992). "Population, Health and Migration”, A Socio-Economic Survey in the Upper East Region with Reference to Drought and Desertification Control in Ghana. Final Report Submitted to the Environmental Protection Council of Ghana. Department of Geography and Resource Development, University of Ghana - Legon, pp 9-51.

Olenja, M. J. (1988). "Malnutrition and Infant Mortality Among the Samia of Busia District of Western Kenya: Methodological and Conceptual Issues”, In Research and Intervention Issues Concerning Infant and Child Mortality and Health. Proceedings of the East Africa Workshop, Co-organized by Muhimbili Centre, Faculty of Medicine, University of Dar-es-Salaam, Tanzania and the International development Research Centre. Manuscript Report 200e, pp 121-132.

Somalia Food Security Analysis Unit (2007). Infant and Young Child Feeding and Health Seeking Practices, Somali Knowledge Attitude Practices Study (KAPS)

Talensi District Assembly (2012). The Composite Budget of the Talensi District Assembly for the 2013 Fiscal Year, Republic of Ghana.

UNICEF (2009a). Tracking Progress on Child and Maternal Nutrition. A survival and development priority, New York, NY 10017, USA.

UNICEF (2009b). Overview of breastfeeding patterns: Proper infant feeding practices are key to child survival. [Online] Available: http://www.childinfo.org/breastfeeding_overview.html (October 13, 2013)

Wardlaw, G.M. (1999). Perspectives in Nutrition. (4 ${ }^{\text {th }}$ ed.). London: McGraw-Hill. 